\title{
Impact of Prehypertension on Carotid Artery Intima Media Thickness
}

\author{
1, Dr Bidhan Ch. Mandal, Md; ${ }^{2,}$ Dr Subhra Prakash Pramanik, Md; \\ ${ }^{3,}$ Dr Arijit Bag, Md; ${ }^{4}$ Prof. Niladri Sarkar; \\ 1,2,3,4, Burdwan Medical College, West Bengal, India
}

\begin{abstract}
Background: Recent evidence supports that the prehypertension is associated with target organ damage, though there is lack of information regarding common carotid artery intima media thickness (CIMT) in prehypertensive individuals. We aimed to study the role of prehypertension in target organ damage in the form of CIMT.

Methods: Carotid CIMT was measured by B-mode ultrasonography by an experienced hand blinded to all clinical data in fifty prehypertensive subjects and compared with fifty normotensive persons and another fifty hypertensive patients.

Result: In this age and sex matched study the mean CIMT of prehypertensivesubjects weresignificantlyhigher compared to normotensive persons $(0.694 \pm 0.048 \mathrm{~mm}$ vs. $0.607 \pm 0.004 \mathrm{~mm}$, $p$ value $<0.001)$. It was highest among hypertensives $(0.736 \pm 0.540 \mathrm{~mm})$ and lowest in normotensive $(0.607 \pm 0.004 \mathrm{~mm})$ persons.

Conclusion: it is clearly seen that there is increased target organ damage in the form of increased CIMT in prehypertensive group and hypertensive group compare to normotensive group justifying separate entity of prehypertension and early treatment of prehypertensive patients.
\end{abstract}

KEY WORDS: carotid artery intima media thickness (CIMT), prehypertension.

\section{INTRODUCTION}

The term "prehypertension" $[1]$ introduced by $7^{\text {th }}$ report of JNC was defined as systolic BP (SBP) 120 $139 \mathrm{~mm}$ of $\mathrm{Hg}$ and diastolic $\mathrm{BP}$ (DBP) of $80-89 \mathrm{~mm}$ of $\mathrm{Hg}$ in more than 2 or more separate reading in two or more separate occasions. The reasoning behind this new category was that long term epidemiological studies has indicated a progressively increasing risk of cardiovascular events [2] on SBP $>110 \mathrm{~mm}$ hg [1]. Although recent evidence support that the pre hypertension is associated with target organ damage[3-5], there is lack of information regarding common carotid artery intima media thickness (CIMT) in pre hypertensive individuals. In this study we want toassess the extent of CIMT in prehypertensive adults in compare to normotensive individuals. Our objective was to establish the role of prehypertension in target organ damage in the form of CIMT, to establish the need for treatment of prehypertension.

\section{METHODS}

In this Institution based comparative observational cross sectional study we evaluated 50 prehypertensive adults and compared them with 50 normotensive persons and also with 50 newly diagnosed (within one month) hypertensive patients from July 2013 to September 2013. Patients attending our medical outpatient departments and indoors aged > 18 years who gave signed informed consent are included in this study.The study protocol was approved by local ethical committeeof our Institution. Patients having diabetes mellitus, known heart diseases, dyslipidemia, obesity $\left(\mathrm{BMI}>30 \mathrm{~kg} / \mathrm{m}^{2}\right)$, renal insufficiency, blood pressure difference in both arms $>20 \mathrm{~mm}$ of $\mathrm{Hg}$ in SBP and $>10 \mathrm{~mm}$ of $\mathrm{Hg}$ in DBP and Hypertensive patients with history of treatment with drugs were excluded from this study.

BP measurement: BP has been measured in each arm using a mercury sphygmomanometer in consecutive 3 days in case of indoor patients and in 1week apart in case of outpatient departments.In each day,BP hasbeen measured three times in both sitting and lying down position and themean value of BP was obtained.Participants were divided in 3 subgroups according to BP level:Normotensive $(<120 / 80 \mathrm{~mm} \mathrm{hg})$, Prehypertensive $(139 \mathrm{~mm} \mathrm{hg} \geq \mathrm{SBP}>120 \mathrm{~mm} \mathrm{Hg}$ and $89 \mathrm{~mm}$ of $\mathrm{hg} \geq \mathrm{DBP}>80 \mathrm{~mm}$ of $\mathrm{Hg}$ ) and Hypertensive $(\mathrm{BP} \geq 140 / 90 \mathrm{~mm} \mathrm{Hg})$. 
Carotid Artery Ultrasonographic Measurements: The left and right CCA were examined in the anterolateral, postero-lateral,andmedio-lateral directions with a high-resolution ultrasoundDoppler system (Acuson 128XP), equipped with a 7-MHz lineararraytransducer. The ultrasonographic assessment of CIMT done byexperienced sonographers blinded to all clinical data in our vascularlaboratory.

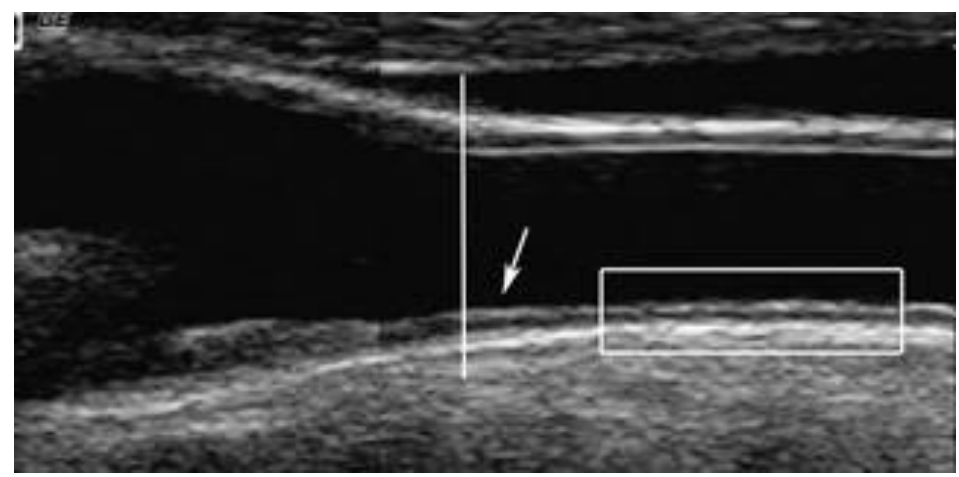

Picture 1: showing common carotid artery intima media thickness.

\section{RESULT}

Table 1: Demographic profile and clinical data of three groups.

\begin{tabular}{|l|l|l|l|l|}
\hline variable & Normotensive & Prehypertensive & Hypertensive & P value \\
\hline Age(in years) & $33.74 \pm 3.89$ & $33.76 \pm 3.77$ & $33.18 \pm 3.81$ & 0.691 \\
\hline Sex(M:F) & $42: 8$ & $43: 7$ & $42: 8$ & 0.949 \\
\hline CIMT( in mm) & $0.607 \pm 0.004$ & $0.694 \pm 0.048$ & $0.736 \pm 0.006$ & $<0.001$ \\
\hline
\end{tabular}

The mean age and gender distribution in three groups of study population were more or less similar and no statistically significant difference was found ( $p$ value 0.691 and 0.949 ). So the study population was age and sex matched.The mean CIMT in prehypertensive patients were $0.694 \pm 0.048 \mathrm{~mm}$, in normotensive persons were $0.607 \pm 0.004 \mathrm{~mm}$ and in hypertensive patients were $0.736 \pm 0.006 \mathrm{~mm}$. The difference was significant after ANOVA test ( $p$ value $<0.001$ ). Applying Tukey HSD as post hoc test for multiple comparisons it is evident that the CIMT of pre-hypertensive group is significantly higher than normotensive group ( $\mathrm{p}$ value $<0.001$ ). CIMT was highest in hypertensive patients and lowest in normotensive individuals ( $\mathrm{p}$ value $<0.001$ and $<0.001$ in both respectively).

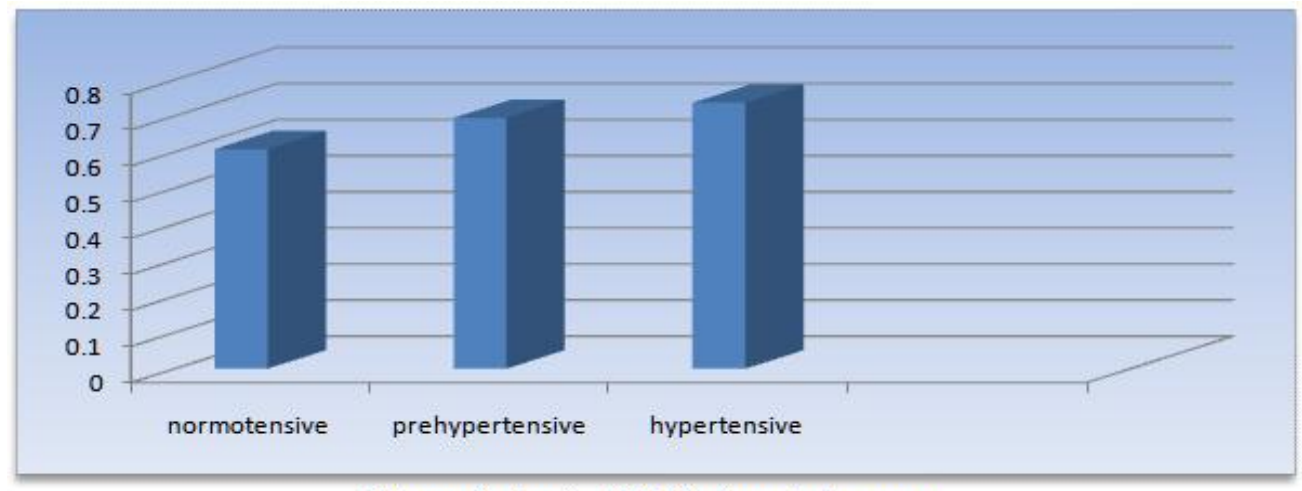

Diagram 1: showing CIMT in three study groups.

\section{DISCUSSION}

JNC 7, issued in 2003, defines a BP of <120/80 mm Hg as "normal" and values from 120/80 to 140/90 mm $\mathrm{Hg}$ as a new category, "prehypertension". JNC 7 may have led to more problems than solutions. The Second National Health and Nutrition Examination Survey (NHANES II) population who met the JNC 7 classification for prehypertension at baseline had a significantly increased risk for all-cause and CV mortality compared with those with normal BP at baseline. When data were adjusted for the presence of risk factors, however, mortality was not increased in individuals who had prehypertension without any additional CV risk factors. the TROPHY (Trial of Preventing Hypertension)study[6] ask loudly for treatment of prehypertension group.Through our study we want to see if there is any positive correlation of prehypertension with common carotid artery intima media thickness to justify the new term "prehypertension". 
Our study showed that prehypertensive subjects had higher CIMT value than their normotensive counterparts, even after adjustment for baseline characteristics.Previous studies have demonstrated associations of prehypertension between inflammatory markers and atherosclerotic disease[7-9]. The authors concludedthat prehypertension might be a proinflammatory condition, promoting subclinical atherosclerotic disease.Our findings indicate that prehypertension may increase therisk of atherosclerosis[10], implying that the increase in CIMT is an earlier preclinical atherosclerotic change. This finding is in line with one report that documented an independent association between borderline hypertension andintima-media thickening. Certain limitations of the present report need to be addressed.According to the guidelines of the JNC-7, the classification of prehypertension requires two or more office visits. In previous study published in Stroke Journal [5]prehypertension was classified during a single office visit, although BP was taken with caution and the average of 3 measures was used.But in our study this limitation has been overcame. But the cross sectional design of the present study does not allow us to establish a cause-effect relationship between prehypertension and carotid intima-media thickening.

\section{CONCLUSION}

In conclusion, it was clearly seen that there was increased target organ damage inthe form of increased CIMT in prehypertensive group compared to normotensive group justifying early treatment of prehypertensive group. Though large scale long term prospective follow up study is required to see the outcome of treatment of prehypertensive patients.

\section{REFERENCES}

[1]. The seventh report of the JointNational Committee on prevention,detection, evaluation and treatment ofhigh blood pressure: The JNC 7 report.JAMA.2003;289:2560-72.

[2]. Chambless LE, Heiss G, Folsom AR, Rosamond W, Szklo M, SharrettAR, Clegg LX. Association of coronary heart disease incidence withcarotid arterial wall thickness and major risk factors: the AtherosclerosisRisk in Communities (ARIC) Study, 1987-1993. Am J Epidemiol.1997;146:483- 494.

[3]. Chambless LE, Heiss G, Folsom AR, Rosamond W, Szklo M, SharrettAR, Clegg LX. Association of coronary heart disease incidence withcarotid arterial wall thickness and major risk factors: the AtherosclerosisRisk in Communities (ARIC) Study, 1987-1993. Am J Epidemiol.1997;146:483-494.

[4]. Greenlund KJ, Croft JB, Mensah GA. Prevalence of heart disease andstroke risk factors in persons with prehypertension in the United States,1999-2000. Arch Intern Med. 2004;164:2113-2118.

[5]. Papamichael, Savas Toumanidis, Elefterios Stamboulis, Konstantinos Vemmos and NikolaosEfstathios Manios, Georgios Tsivgoulis, Eleni Koroboki, Kimon Stamatelopoulos, Christos Zakopoulos. Impact of Prehypertension on Common Carotid Artery Intima-Media Thickness and Left Ventricular Mass. Stroke. 2009;40:1515-1518.

[6]. Julius S, Nesbitt SD, Egan BM, et al; the Trial of Preventing Hypertension (TROPHY) Study Investigators. Feasibility of treating prehypertension with an angiotensin-receptor blocker. N Engl J Med. 2006;354

[7]. Chrysohoou C, Pitsavos C, Panagiotakos DB, Skoumas J, Stefanadis C.Association between prehypertension status and inflammatory markersrelated to atherosclerotic disease. The ATTICA Study.Am J Hypertens.2004;17:568 -573.

[8]. Papadopoulos D, Makris T, Krespi P, Poulakou M, Stavroulakis G,Hatzizacharias A, Perrea D, Votteas V. Adiponectin and resistin plasmalevels in healthy individuals with prehypertension. J ClinHypertens.2005;7:729 -733.

[9]. 9.Pauletto P, Palatini P, Da Ros S, Pagliara V, Santipolo N, Baccillieri S,Casiglia E, Mormino P, Pessina AC. Factors underlying the increase incarotid intima-media thickness in borderline hypertensives. ArteriosclerThrombVasc Biol. 1999;19:1231-1237.

[10]. Wattanakit K, Folsom AR, Chambless LE, Nieto FJ. Risk factors forcardiovascular event recurrence in the Atherosclerosis Risk in Communities (ARIC) study.Am Heart J. 2005;149:606-612. 